\title{
Effect of Nursing Care Guided by Roy's Adaptation Model on Self-Evaluation of Women After Caesarean Section
}

\author{
Amal Mohamed Gamal ${ }^{1 *} \quad$ Gamila Gaber Ayoub ${ }^{2}$ Amal Khalifa Khalil ${ }^{2}$ Afaf Abdel Malek Hussein ${ }^{3}$ \\ 1. assist Prof of Maternal and Newborn Health Nursing, Faculty of Nursing - Menoufia University \\ 2.Lecturer of Maternal and Newborn Health Nursing, Faculty of Nursing - Menoufia University \\ 3.Lecturer of Family and Community Health Nursing, Faculty of Nursing- Menoufia University-Egypt
}

\begin{abstract}
Postpartum caesarean section is a critical time in the women life. During that time, the women need physical and psychological care as well as guidance for healthy practices for their health and newborns. Aim: The study aimed to assess the effect of nursing care guided by Roy's adaptation model on self-evaluation of women after caesarean section. Methods: A quasi-experimental design with pre and post-test was utilized. Sample: A purposive sample of 60 women after caesarean section. Setting: The study was carried out at University and Teaching Hospital at Shebin El-Kom. instruments: An interviewing questionnaire, postpartum follow-up form and post-partum selfevaluation questionnaire Results: There was a highly statistically significant improvement in the post intervention than the pre intervention regarding of puerperium problems and adaptation after cesarean section after implementation of Roy's adaptation model $(\mathrm{P}<0.001)$ Conclusions: The implementation of Roy's adaptation model assisted in stopping the majority of puerperium issues after cesarean section. The difference between most complaints was found to be statistically significant $(\mathrm{p}<0.05 ; \mathrm{p}<0.001)$ during the week of data collection. Recommendations: Roy's adaptation model will be helpful if included incorporated as essential part of routine postpartum care.
\end{abstract}

Keywords: Roy's adaptation model, caesarean section, self-evaluation of women after caesarean section DOI: $10.7176 / \mathrm{JHMN} / 67-05$

Publication date:October $31^{\text {st }} 2019$

\section{Introduction}

A healthful postpartum length influences not only woman's health, but also the fitness of the family and the society (Romero et al., 2012). Caesarean operation becomes obligatory when vaginal delivery is considered risky for the mother and/or the newborn (Clark et al., 2009). In addition, there has been more recent social reasons contributing to a significant increase in caesarean section rate (Christie et al., 2008). However caesarean delivery is an operation carries risks for both the mother and the newborn. Caesarean deliveries usually have unwanted effects, which include increasing maternal mortality rate, medical intervention, increasing the length of hospital stay, and requiring long period for the healing process. Also Late immobilization, higher rate for the risks of infection, late interaction with the newborn and lactation, longer period of transition to oral feeding and increased risk for postpartum complications. These effects negatively affect the mother's physical and psychological health (Barr, 2008).

Postpartum period is a very special phase in the life of the mother and the newborn. It is marked by strong emotions, dramatic physical changes, new relationships and the assumption of adjustment to the new roles. It is a time of making great demands on the woman's resilience and capacity to adapt. Puerperium period can be defined as the first 6 up to 8 weeks after cesarean section, till the anatomic, physiological, and psychological adjustments associated with pregnancy begin to return to the normal. This duration is critical duration for the maternal fitness (Emmanuel et al., 2008). Puerperium period is a difficult time, where new roles and responsibilities are taken, in addition to adapting the physiological changes. During this period, the parents have to be educated about infant care, set up a safe environment for the newborn, learn the new roles, improve the family sensitivity and deal with the issues associated to newborn (Barlow et al.,2010;Rosa et al .,2009).

The first week after delivery, especially the first 24 hours frequently increases the risks for the mother due to the physiological and the psychological changes. Several studies have concluded that it is important for the nurses to follow-up the postpartum women at home. Furthermore, these studies reported that, it is necessary to continue the care given at the health facility at home. By effective nursing care and training, the majority of the troubles that encountered at same point of the postpartum length can be prevented or decreased. In addition, various studies have shown that by providing home care during the postpartum period after early discharge usually, it will result in lower rates of hospitalization (Lieu and Braveman, 2014; Maera et al .,2012).

A standardized and qualified nursing care and training enables the mother at this situation to become more conscious self-care, and competent in motherhood and develop care for herself and the newborn, as well as positive health behaviors and health status. Nurses play an important role for caring the mother during the postpartum period. Therefore, it is important for the nurse to consider both the mother and the newborn regarding the social and psychological requirements of the family (Sercekus and Mete, 1013). To understand these requirements, the 
mother must be intently observed during the postpartum period. Roy adaptation model explains the behavioral responses in four adaptive modes (Kuscu et al., 2015). These are the physiological, the self-concept, the role function and the interdependence adaptive modes. The physiological mode is related to the physical responses displayed with the aid of a person toward the stimulants arising from their environment. The self-concept mode is the combination of an individual's beliefs and feelings about themselves in a precise period. Within the role function mode, Roy described the concept of role as when a person shows the behaviors expected by the society based on his/her role in the society, in order to keep the role, or a person knows how to act when the mother passes from one role to some other. Finally, the interdependence mode includes the relations of the individual with privileged people and the support systems (Gungor and Atherton, 2015). Roy's Adaptation Model has been conducted in numerous studies in various fields and recommended that, it is very beneficial and allows for adaptation. (Lederman and Weingarten,2014).

\subsection{Significance of the study}

The incidence of cesarean section birth had increased in the last 25 years in the world. Maternal complications were increased from $25 \%$ to $50 \%$. According to the consensus of cases of caesarean section in a University Hospital at the Menoufia Governorate during 2012 increased from 1200 to 1300, and in 2013 from 1300 to 1400 case, whilst in 2014 it ranged between 1400 to 1500 case, and in 2018 ranged between 1700 to 1900 case. Therefore, the postnatal period after caesarean section is one of the most critical periods and the neglected phase in the lives of the mothers and the newborn-as prescribed by World Health Organization (WHO). The maternal mortality rate is high in the postpartum period, so special considerations need to be given to the care of the mother and the newborn. In Egypt, while there are studies that had used Roy's Model, but not involving the puerperium women who had caesarean delivery. From this point of view, this study was carried out to assess the effect of nursing care guided by Roy's Adaptation Model on self-evaluation of women after caesarean section.

\subsection{Aim of the study}

The aim of this study was to assess the effect of nursing care guided by Roy's Adaptation Model on self-evaluation of women after caesarean section.

\subsection{Research Hypotheses:}

1- The puerperium women who will follow the nursing care guided by Roy's Adaptation Model after caesarean section will experience fewer puerperium problems compared to before intervention.

2- The puerperium women who will follow the nursing care guided by Roy's Adaptation Model after caesarean section will experience more puerperium adaptation compared to before the intervention.

\section{Subjects and Methods}

\subsection{Research Design}

A Quasi-experimental design with pre and post-test was utilized to accomplish the aim of this study.

\subsection{Research setting}

The current study was conducted at two settings, namely Menoufia University hospital and Shebin El-Kom Teaching hospital and participants home. The subjects was selected from two obstetrics and gynecology department (postpartum unit) one in the Menoufia University hospital and Shebin El-Kom Teaching Hospital, and were followed at their homes.

\subsection{Research Subjects}

A purposive sample of 60 postpartum women who met the inclusion criteria was selected in accordance to the following criteria. Mothers who were willing to take part in the study, aged 20 - 35 years old, free from any disease disabilities, whose infants free from any disorder disabilities, and willing to communicate and cooperate.

\subsection{Tools of the Study}

2.4.1. An interview questionnaire: the researchers developed the interview questions based on an extensive literature review to collect:

A. Socio-demographic data: It included mother's age, educational level, employment condition, mother's gravity, wanted pregnancy, duration of stay in hospital, type of anesthesia, receiving support for domestic work, and receiving support for care of baby.

2.4.2. Postpartum Follow-Up Form: the tool was adopted from (Roy \& Chayaput, 2004)It was used to assess the coping and adaptation after cesarean section. It included 35 questions, adaptive modes have four subparts: the physiological mode (21 questions), the self-concept mode ( 7 question), the role function mode (4 questions) and the interdependence role mode (3 questions). There were two feasible responses (yes and no) for each item. 
2.4.3. Postpartum Self Evaluation Questionnaire (PSEQ): It was developed by Lederman, (1981) to evaluate the adaption of the women in the postpartum period to motherhood. The questionnaire is a 4-point likert scale with eighty two items in total. Postpartum adaption is evaluated in accordance with the points from "1" to "4" (1: Very much 2: Moderately 3: Somewhat 4: Not at all). For the entire questionnaire, the scoring ranges from 82 (minimum) to 328 (maximum). Low scores indicated that the postpartum adaptation was high. Postpartum Self Evaluation Questionnaire (PSEQ) has 7 sub-scales, evaluating postpartum variations of the mothers. Each subscale consists of 10- 13 items. The sub-scales are grouped as; the quality of the relationship between partners, the view of the partners related to collaborating to infant-care, the satisfaction for the birth experience, satisfaction for the continuation of life, trusting the energy in coping with motherhood duties, satisfaction for the motherhood and neonatal care and support of the family and the friends for motherhood.

\subsection{Validity and reliability}

For validity purposes, the researchers conducted an extensive literature review and developed the questionnaire from the previously used toolsand reviewing pertinent studies. An interview questionnaire was designed by the researchers and validated by five experts in the field of maternal and newborn health nursing and community health nursing in the Faculty of Nursing of Menoufia University for content validity. While postpartum Follow-Up Form and Postpartum Self Evaluation Questionnaire (PSEQ) were adopted from previous study.Lederman(1981) The interview questionnaire underwent some modifications according to the panel of judgment regarding the clarity of sentences and appropriateness of content.

\subsection{Pilot study}

A pilot study was conducted to test the feasibility, applicability and understandability of the tools. It was once conducted on $10 \%$ of the total sample according to the selection criteria. All women participated in the pilot study were excluded from the study sample.

\subsection{Ethical Considerations}

The researchers followed all the ethical principles in conducting the study. Informed consent was obtained from the mothers who were willing to take part in the study. Participation in the study was voluntary. They were reassured that any obtained information would be exclusive and would only be utilized for the study purpose. Participants were given a colored booklet about self care and baby care to be used as a guide.

\subsection{Data collection procedures :}

The current study was carried out on seven phases:

\section{Preparatory phase:}

The researchers performed an extensive review of related literature to cover the various aspects of the research problem and to develop the nursing care guided by Roy's Adaptation Model (RAM).

\section{Interviewing phase:}

The researchers collected the data from the postpartum women using an interviewing questionnaire, postpartum follow-up form and post-partum self-evaluation questionnaire.

\section{Implementation phase:}

1. The data collection started from April 2018 till Jule 2018.

2- A letter was addressed about the purpose of the study from Dean of Faculty of Nursing, Menoufia University to the dean and chairmen of obstetrics and gynecology department of University hospital and Shebin El-Kom teaching hospital for their cooperation and permission to conduct the study. Also, meetings were conducted with the heads of departments' which had been chosen in each hospital to explain the purpose of the study and methods of data collection to acquire permission for conducting the study.

3- After obtaining the approval and the informed consent to conduct the study, the researchers initiated the information series process from the women who fulfilled the inclusion criteria. The researchers held meetings with the women in the postpartum unit.

4- Before filling the questionnaire, the researchers introduced themselves to the mothers. Then short description of the purpose of the study and the kind of questionnaire required to complete were explained to the mothers to gain their cooperation. Questionnaires were filled from the selected participants.

5-Data collection was done through interviewing the mothers in postpartum unit approximately 24 hours after their caesarean section. The average time taken for completing the questionnaires was about 20-30 minutes.

6-The collected data used as the baseline assessment (pre - test).

7-The researchers developed the nursing care guided by RAM aimed to minimize or prevent puerperium problems and to improve puerperium adaptation after their caesarean section. The postpartum follow-up form and postpartum self-evaluation form was once used in constructing the nursing discharge plan to be done in the homes of the 
postpartum women after discharge. These intervention was given to the postpartum women during seven home visits in total (twice in the first week after delivery and once in the $2 \mathrm{nd}, 3 \mathrm{rd}, 4 \mathrm{th}, 5 \mathrm{th}$ and $6 \mathrm{th}$ weeks). At the end of each visit, the subsequent visit's appointment was taken and telephone numbers of the researchers were given to the postpartum women if they want to contact with them at any time.

8-Appropriate individualized approved by North American Nursing Diagnosis Association (NANDA) were prepared, depending on the individual need and used, in the nursing care given to the postpartum women.

9-Each session consisted of a 20 -minutes power point presentation on lab top

device and a subsequent 20-minutes group discussion for answering the women's questions. A copy of the instructional intervention booklet was developed and prepared by the researchers after reviewing the associated literature and written in easy Arabic language supported by illustrative drawing used to facilitate the process of education that introduced to each mother, to motivate the mother, help for reviewing, and help educating at home. At the end of each visit an appointment was made for the subsequent visit.

10 -Essential interventions were maintained for the continuing diagnoses. Nursing interventions focusing on newly going on diagnoses and viable new diagnoses were made as required and these was evaluated for the duration of the following visit.

11-Postpartum Follow-up Form and self-evaluation form was used in evaluating the intervention results. If the recognized problem had resolved, evaluation was made, if not, revision of the nursing diagnosis was made and the suitable intervention was made and evaluated .

12-Existing diagnoses and potential new diagnoses were evaluated by the postpartum follow-up form and postpartum self-evaluation questionnaire. During each visit the diagnoses determined at the previous visit were evaluated concerning their resolution.

4) Evaluation phase:

- The postpartum women were followed up by the researchers through face-to-face and telephone contacts for answering any question and promoting their adherence to the delivered education sessions. Women also received routine postpartum care. Finally, all women selected were instructed to complete the posttest questionnaire .

\subsection{Statistical Data Analysis}

The data collected were tabulated \& analyzed using SPSS (version 22).-Quantitative data were expressed as mean $\&$ standard deviation $(\mathrm{X} \pm \mathrm{SD})$. Qualitative data were expressed as number and percentage and analyzed by applying chi-square test, and whenever testing proportions $\mathrm{Z}$ test was applied. $\mathrm{t}$ test were used for comparing the pretestposttest mean scores and chi-square test was used for comparing the nursing diagnoses The level of significance was set at $\mathrm{p}<0.05$.

Limitation of the study:

Lack of recent references wither in Arab countries or western countries that used Roy's adaptation model. 
3.Results:

Table I: Demographic characteristics of the study participants $(n=60)$

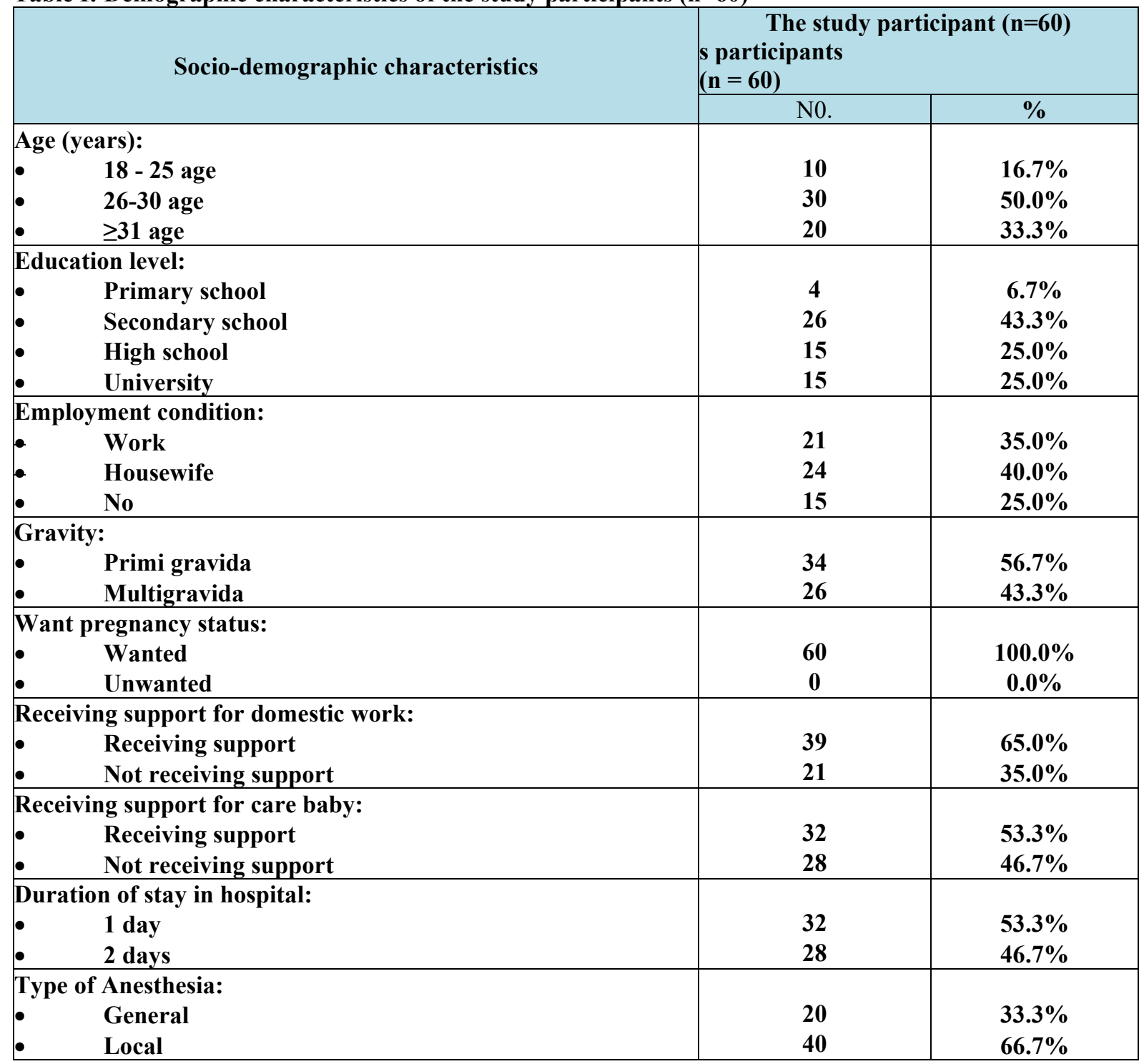

Table (1) showed that $50 \%$ of the study participants were between $26-30$ year. Regarding to their educational level and occupation, $43.3 \%$ of the study sample had secondary school education and $40 \%$ of them were housewife, Concerning gravida, $56.7 \%$ of them were primigravida while, more than half of the study sample received support for care of the new born and $66.7 \%$ of them had local anesthesia. 
Table 2: Distribution of the study participants regarding NANDA nursing diagnosis ( physiological mode) based on Roy adaptation model identified in the first meeting and last meeting $(n=60)$.

\begin{tabular}{|c|c|c|c|c|c|c|c|c|c|c|}
\hline \multirow[t]{3}{*}{ Variables } & \multirow[t]{3}{*}{ Nursing diagnosis } & \multicolumn{4}{|c|}{ First Meeting } & \multicolumn{4}{|c|}{ Last Meeting } & \multirow{3}{*}{$\begin{array}{c}\text { P- } \\
\text { Value }\end{array}$} \\
\hline & & \multicolumn{2}{|r|}{ Yes } & \multicolumn{2}{|c|}{ No } & \multicolumn{2}{|c|}{ Yes } & \multicolumn{2}{|c|}{ No } & \\
\hline & & N0. & $\%$ & No. & $\%$ & N0. & $\%$ & No. & $\%$ & \\
\hline \multirow{21}{*}{$\begin{array}{r}\text { Physiological } \\
\text { mode }\end{array}$} & 1- Risk for infection & 60 & $100 \%$ & 0 & $0.0 \%$ & 0 & $0.0 \%$ & 60 & $100 \%$ & 0.000 \\
\hline & $\begin{array}{ll}2- & \text { Risk for transmitting } \\
\text { infection }\end{array}$ & 40 & $66.7 \%$ & 20 & $33.3 \%$ & 1 & $1.7 \%$ & 59 & $98.3 \%$ & 0.000 \\
\hline & 3- $\quad$ Ineffective breast feeding & 20 & $33.3 \%$ & 40 & $66.7 \%$ & 0 & $0.0 \%$ & 60 & $100 \%$ & 0.000 \\
\hline & 4- $\begin{array}{l}\text { Interruption of breast- } \\
\text { feeding }\end{array}$ & 50 & $83.3 \%$ & 10 & $16.7 \%$ & 7 & $11.7 \%$ & 53 & $88.3 \%$ & 0.000 \\
\hline & $\begin{array}{l}\text { 5- Imbalanced nutrition: less } \\
\text { than body requirement. } \\
\text { 6- body requirement }\end{array}$ & 49 & $81.6 \%$ & 11 & $18.3 \%$ & 12 & $20 \%$ & 48 & $80 \%$ & 0.000 \\
\hline & $\begin{array}{l}\text { 6. Imbalanced nutrition: more } \\
\text { than body requirement. } \\
\text { 7- } \text { body requirement }\end{array}$ & 20 & $33.3 \%$ & 40 & $66.7 \%$ & 0 & $0.0 \%$ & 60 & $100 \%$ & 0.000 \\
\hline & 7- $\quad$ Self-care deficit (Bathing) & 22 & $36.7 \%$ & 38 & $63.3 \%$ & 0 & $0.0 \%$ & 60 & $100 \%$ & 0.000 \\
\hline & 8- Self-care deficit (Hygiene) & 25 & $41.7 \%$ & 35 & $58.3 \%$ & 0 & $0.0 \%$ & 60 & $100 \%$ & 0.000 \\
\hline & 9- $\quad$ Disturbed sleep pattern & 50 & $83.3 \%$ & 10 & $16.7 \%$ & 4 & $6.7 \%$ & 56 & $93.3 \%$ & 0.000 \\
\hline & 10- Fatigue & 20 & $33.3 \%$ & 40 & $66.7 \%$ & 2 & $3.3 \%$ & 58 & $96.7 \%$ & 0.000 \\
\hline & $\begin{array}{l}\text { 11- Changes in comfort-Pain } \\
\text { (Abdomen) }\end{array}$ & 60 & $100 \%$ & 0 & $0.0 \%$ & 3 & $5.0 \%$ & 57 & $95.0 \%$ & 0.000 \\
\hline & $\begin{array}{l}\text { 12- Changes in comfort-Pain } \\
\text { (Breast) }\end{array}$ & 11 & $18.3 \%$ & 49 & $81.7 \%$ & 2 & $3.3 \%$ & 58 & $96.7 \%$ & 0.008 \\
\hline & 13- Constipation & 22 & $36.7 \%$ & 38 & $63.3 \%$ & 0 & $0.0 \%$ & 60 & $100 \%$ & 0.000 \\
\hline & 14- Urinary retention & 7 & $11.7 \%$ & 53 & $88.3 \%$ & 0 & $0.0 \%$ & 60 & $100 \%$ & 0.006 \\
\hline & $\begin{array}{l}\text { 15- Functional } \\
\text { Incontinence(Urinary) }\end{array}$ & 2 & $3.3 \%$ & 58 & $96.7 \%$ & 0 & $0.0 \%$ & 60 & $100 \%$ & 0.154 \\
\hline & $\begin{array}{ll}\text { 16- Stress } & \text { incontinence } \\
\text { (Urinary) }\end{array}$ & 5 & $8.3 \%$ & 55 & $91.7 \%$ & 1 & $1.7 \%$ & 59 & $98.3 \%$ & 0.094 \\
\hline & $\begin{array}{l}\text { 17- Ineffective therapeutic } \\
\text { regimen management }\end{array}$ & 0 & $0.0 \%$ & 60 & $100 \%$ & 0 & $0.0 \%$ & 60 & $100 \%$ & - \\
\hline & 18- Deficient fluid volume & 55 & $91.7 \%$ & 5 & $8.3 \%$ & 0 & $0.0 \%$ & 60 & $100 \%$ & 0.000 \\
\hline & 19- Impaired skin integrity & 60 & $100 \%$ & 0 & $0.0 \%$ & 0 & $0.0 \%$ & 60 & $100 \%$ & 0.000 \\
\hline & $\begin{array}{l}\text { 20- Ineffective } \\
\text { maintenance }\end{array}$ & 32 & $53.3 \%$ & 28 & $46.7 \%$ & 0 & $0.0 \%$ & 60 & $100 \%$ & 0.000 \\
\hline & 21- Impaired physical mobility & 60 & $100 \%$ & 0 & $0.0 \%$ & 0 & $0.0 \%$ & 60 & $100 \%$ & 0.000 \\
\hline
\end{tabular}

Table (2) illustrated that there was statistically significant improvement $(\mathrm{p}<0.000)$ regarding all items of the physiological adaption mode after last meeting compared to the first meeting except the items "functional incontinence and stress incontinence ". Which did not show any significant difference $(\mathrm{P}>0.05)$. 
Table 3: Continue. Distribution of the study participants regarding NANDA nursing diagnosis (selfConcept, role function and interdependence mode) based on Roy adaptation model identified in the first meeting and last meeting $(\mathbf{n}=\mathbf{6 0})$.

\begin{tabular}{|c|c|c|c|c|c|c|c|c|c|c|}
\hline \multirow[t]{3}{*}{ Variables } & \multirow[t]{3}{*}{ Nursing diagnosis } & \multicolumn{4}{|c|}{ First Meeting } & \multicolumn{4}{|c|}{ Last Meeting } & \multirow{3}{*}{$\begin{array}{c}\text { P- } \\
\text { Value }\end{array}$} \\
\hline & & \multicolumn{2}{|c|}{ Yes } & \multicolumn{2}{|c|}{ No } & \multicolumn{2}{|c|}{ Yes } & \multicolumn{2}{|c|}{ No } & \\
\hline & & N0. & $\mathbf{\%}$ & N0. & $\%$ & No. & $\%$ & No. & $\%$ & \\
\hline \multirow{7}{*}{$\begin{array}{l}\text { self- concept } \\
\text { mode }\end{array}$} & Loneliness & 10 & $16.7 \%$ & 50 & $83.3 \%$ & $\mathbf{0}$ & $0.0 \%$ & 60 & $100 \%$ & 0.001 \\
\hline & Situational low self-esteem & 11 & $18.3 \%$ & 49 & $81.7 \%$ & 1 & $1.7 \%$ & 59 & $98.3 \%$ & 0.002 \\
\hline & $\begin{array}{l}\text { 3. Knowledge deficit } \\
\text { ( Nutrition) }\end{array}$ & 38 & $63.3 \%$ & 22 & $36.7 \%$ & $\mathbf{0}$ & $0.0 \%$ & 60 & $100 \%$ & 0.000 \\
\hline & $\begin{array}{l}4 . \quad \text { Knowledge } \\
\text { (Hygiene) }\end{array}$ & 20 & $33.3 \%$ & 40 & $66.7 \%$ & $\mathbf{0}$ & $0.0 \%$ & 60 & $100 \%$ & 0.000 \\
\hline & $\begin{array}{l}\text { 5. Knowledge deficit (Breast } \\
\text { feeding) }\end{array}$ & 40 & $66.7 \%$ & 20 & $33.3 \%$ & $\mathbf{0}$ & $0.0 \%$ & 60 & $100 \%$ & 0.000 \\
\hline & $\begin{array}{l}\text { 6. Knowledge deficit (Family } \\
\text { planning) }\end{array}$ & $\mathbf{0}$ & $0.0 \%$ & 60 & $100 \%$ & $\mathbf{0}$ & $0.0 \%$ & 60 & $100 \%$ & - \\
\hline & 7. $\quad$ Disturbed body image & $\mathbf{0}$ & $0.0 \%$ & 60 & $100 \%$ & 5 & $8.6 \%$ & 53 & $91.4 \%$ & $\mathbf{0 . 0 2 0}$ \\
\hline \multirow{4}{*}{$\begin{array}{l}\text { Role function } \\
\text { mode }\end{array}$} & 1- $\quad$ Care giver role strain & 39 & $65.0 \%$ & 21 & $35.0 \%$ & 2 & $3.3 \%$ & 58 & $96.7 \%$ & 0.000 \\
\hline & 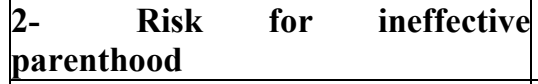 & 9 & $15.0 \%$ & 51 & $85.0 \%$ & $\mathbf{0}$ & $0.0 \%$ & 60 & $100 \%$ & 0.002 \\
\hline & \begin{tabular}{|l} 
3- Impaired \\
maintenance
\end{tabular} & 19 & $31.7 \%$ & 41 & $68.3 \%$ & 60 & $100 \%$ & $\mathbf{0}$ & $0.0 \%$ & 0.000 \\
\hline & 4- $\quad$ Social isolation & 20 & $33.3 \%$ & 40 & $66.7 \%$ & $\mathbf{0}$ & $0.0 \%$ & 60 & $100 \%$ & \begin{tabular}{|l|l|l}
0.000 \\
\end{tabular} \\
\hline \multirow[t]{3}{*}{$\begin{array}{l}\text { Interdependence } \\
\text { Mode }\end{array}$} & \begin{tabular}{|lll} 
1- Change the role of \\
parental
\end{tabular} & 17 & $28.3 \%$ & 43 & $71.7 \%$ & $\mathbf{0}$ & $0.0 \%$ & 60 & $100 \%$ & 0.000 \\
\hline & \begin{tabular}{|lr}
$2-\quad$ Interruption & family \\
processes
\end{tabular} & 15 & $25.0 \%$ & 45 & $75.0 \%$ & 0 & $0.0 \%$ & 60 & $100 \%$ & 0.000 \\
\hline & \begin{tabular}{|llll}
$3-$ & Conflict the role of \\
parental
\end{tabular} & 0 & $0.0 \%$ & 60 & $100 \%$ & 0 & $0.0 \%$ & 60 & $100 \%$ & - \\
\hline
\end{tabular}

Table (3) reflected that there was statistically significant improvement $(\mathrm{p}<0.000)$ regarding all items of self- concept, role function and interdependence mode after the last meeting compared to the first meeting, except the items "disturbed body image". Which did not show this significant difference $(\mathrm{P}>0.05)$.

Table 4. Comparison of pretest and posttest mean scores of postpartum self-evaluation questionnaire of the study participants $(n=60)$.

\begin{tabular}{|c|c|c|c|c|}
\hline Post-Partum Self Evaluation Questionnaire & $\frac{\text { Pretest }}{\text { Mean } \pm \text { SD }}$ & $\frac{\text { Posttest }}{\text { Mean } \pm \text { SD }}$ & t-test & p.value \\
\hline $\begin{array}{l}\text { 1- The quality of the relationship } \\
\text { between partners }\end{array}$ & $46.30 \pm 1.97$ & $33.90 \pm 2.96$ & 31.8 & $<0.001$ \\
\hline $\begin{array}{l}\text { 2- The view of the partners regarding } \\
\text { participating to infant-care }\end{array}$ & $41.91 \pm 1.2$ & $32.02 \pm 2.4$ & 29.9 & $<0.001$ \\
\hline $\begin{array}{l}\text { 3- The satisfaction for the birth } \\
\text { experience }\end{array}$ & $40.1 \pm 1.2$ & $29.21 \pm 2.5$ & 29.3 & $<0.001$ \\
\hline $\begin{array}{l}\text { 4- Satisfaction for the continuation of } \\
\text { life }\end{array}$ & $42.1 \pm 1.7$ & $36.9 \pm 2.06$ & 3.9 & $<0.001$ \\
\hline $\begin{array}{l}\text { 5- Trusting the power in coping with } \\
\text { motherhood duties }\end{array}$ & $52.9 \pm 2.1$ & $38.95 \pm 2.91$ & 34.2 & $<0.001$ \\
\hline $\begin{array}{l}\text { 6- Satisfaction for the motherhood and } \\
\text { neonatal Care }\end{array}$ & $48.95 \pm 2.3$ & $38.99 \pm 2.96$ & 17.6 & $<0.001$ \\
\hline $\begin{array}{l}\text { 7- Support of the Family and the friends } \\
\text { for motherhood }\end{array}$ & $46.02 \pm 2.05$ & $39.08 \pm 1.95$ & 25.95 & $<0.001$ \\
\hline
\end{tabular}




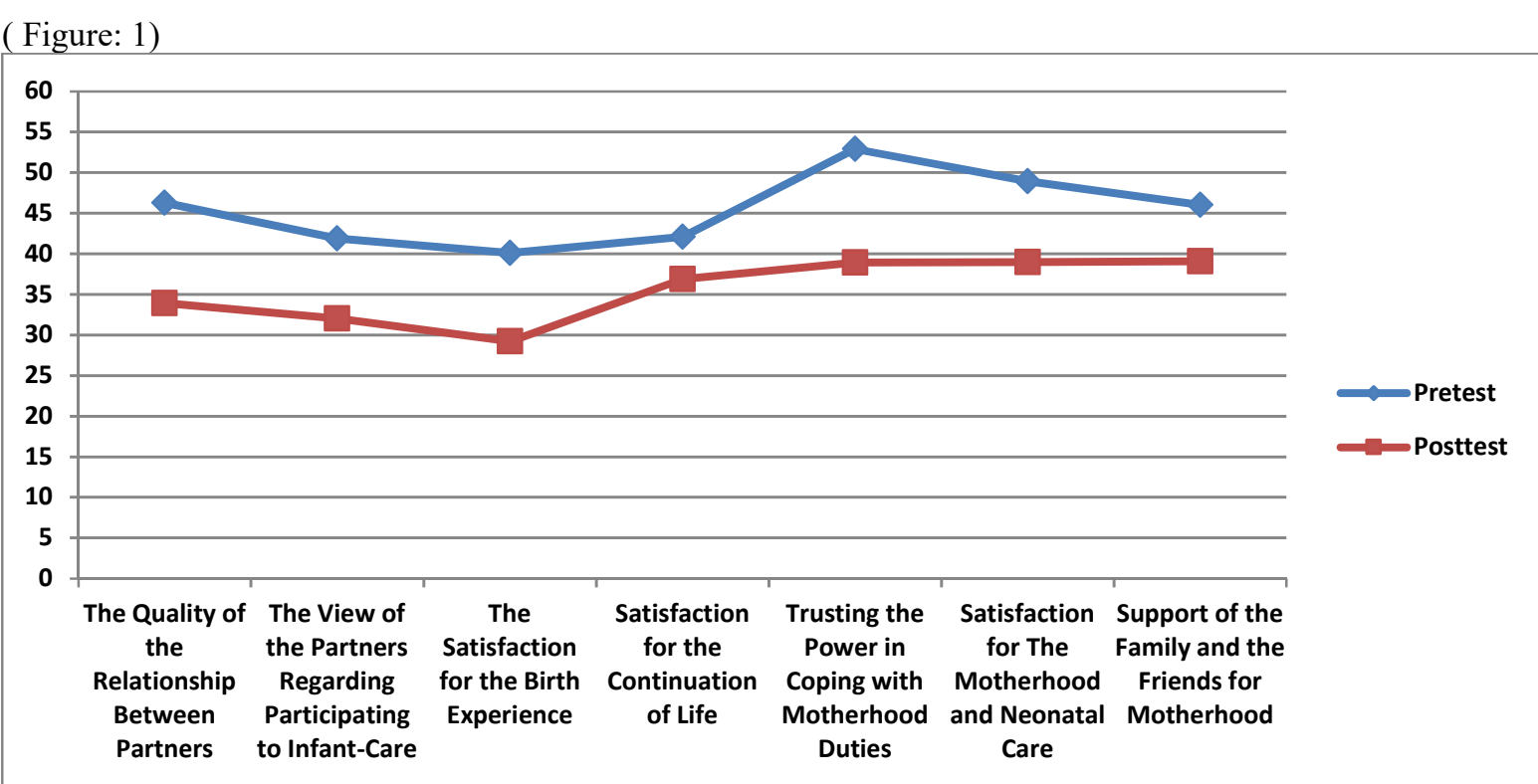

Table (4): reflected that there was highly statistical significant improvement between pre and post -tests regarding all items of PSEQ.

Figure (2)

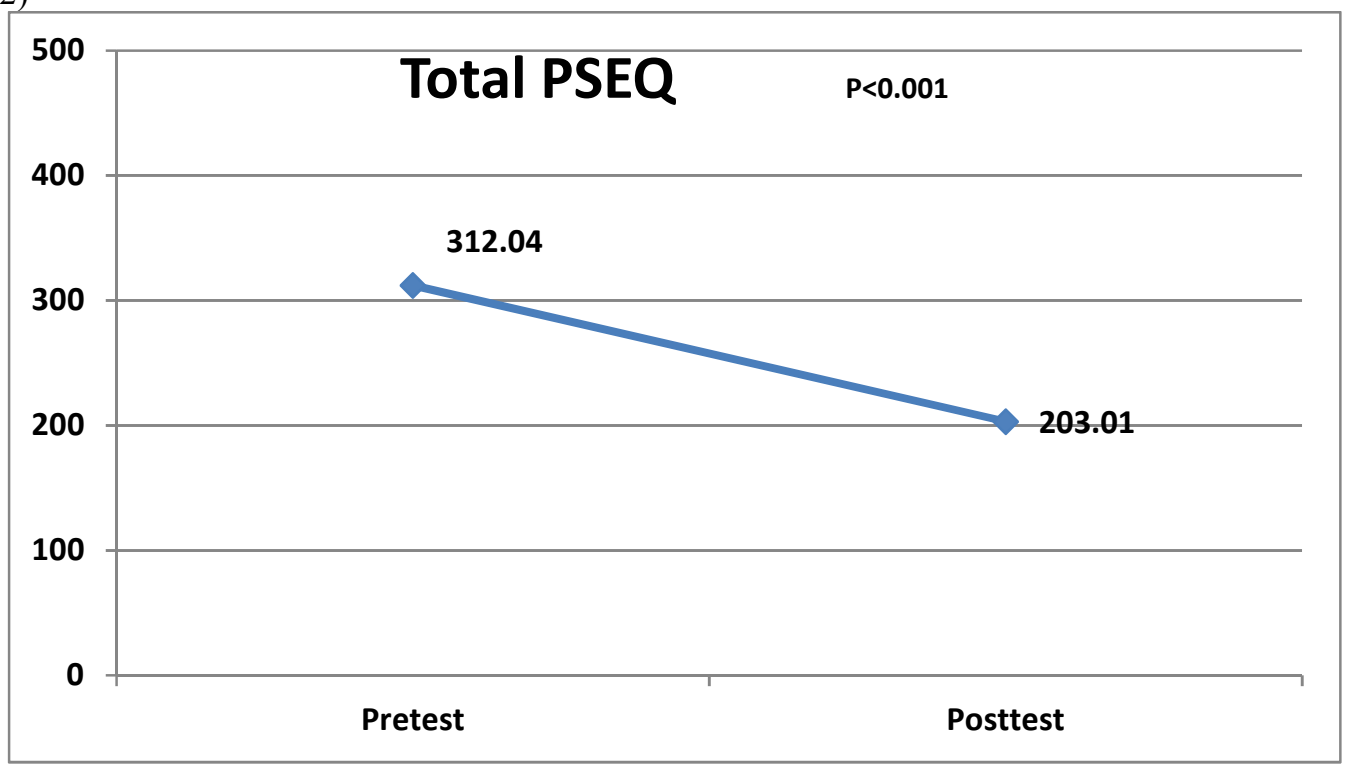

Figure (2) reflects that there were highly statistically significant differences between pre and post -tests regarding all terms items of PSEQ

\section{Discussion}

Quality of care of the postpartum women can have a significant impact on the mother's physical recovery and emotional wellbeing. This care also helps the couples sense greater connected and assured in their early parenting skills. Parental satisfaction reduces the risk of emotional problem for the newborn and other family members. Studies also confirmed that the postpartum care increases the coping capabilities and bonding between the mother and newborn. The present study followed the same goal to investigate the effect of one of the nursing models' "Roy adaptation model" could efficiently plays a pivotal role in decreasing and eliminating the related problems associated with the postpartum periods by establishing home health care through the postpartum visits. (Akman and Ozerk,2015).

Concerning gravida, $56.7 \%$ of them were Primigravida this could be due to the age selected for the study. More than half of the study sample received support for care of the new born this could be because family members share in caring for the mother and baby and delivery is a happy family event. This finding was consistent with Apay \& Pasinlioglu (2014) who conducted an intervention study using Roy's Model to evaluate the care given to postpartum women following caesarean delivery.Also (Barone et al., 2011). Found that 35\% of the mothers 
were Primigravida, 39\% of them were received support for care of the new born.

In relation to NANDA nursing diagnosis of postpartum women (physiological mode, self-concept, role function and interdependence mode) the current study revealed that after nursing care guided by Roy's adaptation model, there were statistically significant improvement $(p<0.000)$ regarding all items of the physiological mode such as: Risk for infection, change in comfort pain, disturbed sleep pattern, constipation, urinary retention, However the items "functional incontinence and stress incontinence" did not show this significant improvement $(\mathrm{P}>0.05)$. This finding was in agreement with Apay \& Pasinlioglu , (2014) they found that after intervention, the diagnoses of the postpartum women in the experimental group in the first and the last interviews regarding all items of the physiological mode was found to be statistically significant $(p<0.001, p<0.05)$, while there was no significant difference between diagnoses of constipation, functional incontinence and stress incontinence $(p>$ 0.05).This finding could be because in Egyption culture they focus on

Regarding to NANDA nursing diagnosis of postpartum women (self-concept, role function and interdependence mode) the current study revealed that after nursing care guided by Roy's adaptation model, there were statistical significant improvement $(\mathrm{p}<0.000)$ regarding all items of the self-concept, role function and interdependence mode except the item of "disturbed body image". Which did not show this significant difference ( $\mathrm{P}>0.05)$. This finding was consistent with Mohammadpour,et al., (2016) they studied "The effects of the Roy's Adaptation Model on primigravida women's self-Concept: A Randomized Controlled Trial" in Iran. They found that the study intervention significantly promoted women's self-concept adaptation "Physical Self, Interpersonal Self, and Self-concept Mode" in which self-concept scores in the control group increased, the scores in the experimental group decreased significantly after the study (P-value $<0.01$ ). Additionally, This finding was in agreement with Apay \& Pasinlioglu, (2014) they found that after the intervention, the diagnoses of the postpartum women in the experimental group in the first and the last interviews regarding all items of the (self-concept, role function and interdependence mode) was found to be statistically significant $(p<0.001, p<0.05)$, while there was no significant difference between diagnose of disturbed body image $(p>0.05)$. This could due to the presence of the scare and the engorgement of breast which interfere with body image.

Regarding to pretest and posttest mean scores of postpartum self-evaluation questionnaire of the study participants the current study revealed that after nursing care guided by Roy's adaptation model, there were statistically significant improvement $(p<0.000)$ in all items of the PSEQ. This finding was in agreement with Capik et al., (2015) who found that there was no significant difference between experimental and control groups in terms of pretest mean scores of total PSEQ and its sub-scales ( $>>0.05)$; while, there was a statistically significant difference between these groups in terms of posttest mean scores of total PSEQ and all other sub-scales except for "satisfaction for the continuation of life" $(\mathrm{p}<0.05)$; and mean scores given by those in the experimental group after the care were positive

Finally, according to the assumptions of the Roy model, the problems were dealt with in four adaptation modes: physiological, self-concept, role function and interdependence. The purpose of the nursing care was to help the postpartum women to achieve the adaptation process in all modes. The ability to cope and achieve all levels of adaptation was also one of the objectives in the process of nurturing and it also means that all the assumptions of the model were fulfilled and the two hypothesis were correct .

\section{Conclusions}

Based on the results of this study, it was concluded that, there was a highly statistically significant improvement between pre and post intervention $(p<0.001)$ regarding of puerperium problems and adaptation following cesarean section after implementation of Roy's adaptation model which validate the study hypothesis.

\section{Recommendation}

According to the findings of the present study and conclusion, the following recommendations are proposed:

1- Roy's adaptation model could be helpful incorporated as an essential part of routine postpartum care.

2- Providing comprehensive training programs for the nurses during routine postpartum care and follow up after cesarean section about Roy's adaptation model.

3-Future studies should be conducted in different geographical regions \& on a larger sample group.

\section{References References}

1- Romero A., Rodriguez L., and Cardenas C. (2012): Coping and adaptation process during puerperium, Colomb Med .43(2): 167-174.

2- Clark A., Skouteris A., Wertheim E., Paxton S.,and Milgrom J.(2009): My baby body A qualitative insight into women's body-related experiences and mood during pregnancy and the postpartum. J Re-prod Infant Psychol. 27: $330-333$.

3-Christie J., Poulton B.,and Bunting B.(2008): An integrated mid-range theory of postpartum family developmenta guide for research and practice. J Adv Nurs.;61:38-50. 
4-Barr J.A.(2008): Postpartum depression, delayed maternal adaptation, and mechanical infant caring a phenomenological hermeneutic study. Int J Nurs Stud.;45:362-369

5-Emmanuel E., Creedy D., John W., Gamble J.,and Brown C. (2008):Maternal role development following childbirth among Australian women. J Adv Nurs. 2008; 84:18-26.

6- Barlow J., Coren E.,and Brown S. (2010):Parent-training programmes for improving maternal psychosocial health (Cochrane Review) The Cochrane Library; pp. 4-4.

7-Lieu T.A., and Braveman P.A. (2014) :A Randomized Comparison of Home and Clinic Follow-Up Visits after Early Postpartum Hospital Discharge: Part I. Pediatrics, 105, 1058-1065. http://dx.doi.org/10.1542/peds.105.5.1058

8-Maera E., Kotagal U.R. and Atherton H.D. (2012): Impact of Early Discharge Legislation and Early Follow-Up Visits on Infant Outcomes. Pediatrics, 113, 1619-1630. http://dx.doi.org/10.1542/peds.113.6.1619 [Citation Time(s):1]

9-Sercekus P., Mete S.( 1013): Effects of antenatal education on maternal prenatal and postpartum adaptation. J Advanced Nursing. 66(5):999-1010.

10-Kuscu M.K., Akman I., Karabekiroglu A., Yurdakul Z., Orhan L., Özdemir N., Akman M. and Ozerk E. ( 2015) Early adverse emotional response to childbirth in Turkey: the impact of maternal attachment styles and family support. Journal of Psychosomatic Obstetrics \& Gynecology 29, 33- 38.

11-Gungor R.P. \& Atherton E. ( 2015) Dimensions of postpartum adaptation: comparisons of multiparas 3 days and 6 weeks after cesarean delivery. Journal of Psychosomatic Obstetrics and Gynaecology 7, 193- 203.

12-Lederman R.P.,and Weingarten C.T. ( 2014) Postpartum self evaluation questionnaire: measures of maternal adaptation. Birth Defects: Original Article Series 17, 201- 231.

13-Lederman E. (1981): The Roy Adaptation Model and Research. Nursing Science Quarterly, 22, $209-211$. http://dx.doi.org/10.1177/0894318409338692

14-Roy E.G. and Chayaput, E. (2011) Early Postpartum Discharge: How Are Mothers Managing? Journal of Obstetric, Gynecologic, and Neonatal Nursing27,142-148.

15-Apay, S.E. and Pasinlioglu, T.(2014) :Using Roy's Model to Evaluate the Care Given to Postpartum Women Following Caesarean Delivery. Department of Obstetric and Gynecological Nursing, Faculty of Health Science, Ataturk University, Erzurum, Turkey .Open Journal of Nursing, 4, 784-796. available at http://dx.doi.org/10.4236/ojn. 411084

16- Mohammadpour, A , Najafi S., Tavakkolizadeh J \& Mohammadzadeh F.(2016): The Effects of the Roy's Adaptation Model on Primigravida Women's Self-Concept: A Randomized Controlled Trial, Asian Journal of Pharmaceutical Research and Health Care, Vol 8(S1), 17-23, 2016 ISSN (Online) : 2250-1460 DOI: 10.18311/ajprhc/7717 available at www.informaticsjournals.com/index.php/ajprh

17-Çapik A., Nazik E.,\& Özdemir,F.(2015): The Effect of the Care Given Usıng Orem's Self-Care Model on the Postpartum Self- Evaluation, Ataturk University Faculty of Health Science, Department of Midwifery, Erzurum, MA 25100, Turkey. International Journal of Caring Sciences May-August Volume 8 Issue 2 available at www.internationaljournalofcaringsciences.org

18- Akman M. and Ozerk E. ( 2015) Early adverse emotional response to childbirth in Turkey: the impact of maternal attachment styles and family support. Journal of Psychosomatic Obstetrics \& Gynecology 29, 3338.

19- Barone, S.H., Roy, C.L. and Frederickson, K.C. (2011): Instruments Used in Roy Adaptation Model-Based Research: Review, Critique and Future Directions. Nursing Science Quarterly, 21, 353-362. http://dx.doi.org/10.1177/0894318408323491 [Citation Time(s):

20- Rosa, I.A., Perry, J. and Johnson, V. (2009) Benefits of Increased Home-Visitation Services: Exploring a Case Management Model. Family and CommunityHealth32,58-75. http://dx.doi.org/10.1097/01.FCH.0000342817.95390.7e 